\title{
The effects of COVID-19 on EU federalism
}

\author{
Juan Carlos MARTÍN*, Concepción ROMÁN**
}

\begin{abstract}
This article analyses how COVID-19 is affecting the EU federalism position in 21 Member States. The analysis is based on an ordered probit econometric model that explains the citizens' support to a major involvement of the EU institutions to control the corona virus pandemic. The dataset is the product of a survey administered to 21804 European citizens about a number of issues about the pandemic in $21 \mathrm{EU}$ countries. The empirical analysis provides conclusive evidence on the determinants that affect the individual shift position of European citizens to a major involvement of the European institutions in the control of the pandemic. Our results show that Portuguese, Greeks, Bulgarians, Italians and Spaniards and males are those more in favour of the EU federalist solution to control the COVID-19 crisis. Years of education and social class are among the variables that do not have any significant effect. Meanwhile, the political support to the national government, the priority given to health vs. economy and, being in favour of limiting individual rights to control the pandemic seem to have a positive effect on EU federalism. Moreover, concerns about being infected by the pandemic, need of the help of others, altruism (helping others), economic loss, and social interaction with others also play a determinant role. Thus, the article contributes to the debate of the attitudes and behaviour that affect the individual position of the citizens who want a shift in authority from the national governments to the federal EU as a link to create more resilient regions during COVID-19.
\end{abstract}

Keywords: COVID-19 pandemic, ordered probit, micro-econometric analysis, marginal effects, EU federalism, resilience

\section{Introduction}

Since March 2020 when the World Health Organization (WHO) declared "COVID-19" as a global pandemic (WHO, 2020a, b), the world is experiencing a

\footnotetext{
*Juan Carlos MARTÍN is Professor at the University of Las Palmas de Gran Canaria, Spain; e-mail: jcarlos.martin@ulpgc.es.

${ }^{* *}$ Concepción ROMÁN is Professor at the University of Las Palmas de Gran Canaria, Spain; e-mail: concepcion.roman@ulpgc.es.
} 
crisis that is making governments to trade-off between the health damage of the pandemic and the economic consequences of controlling it with lockdown measures. The health system resilience has been affected by the financial cuts pursued in many countries after the 2008 financial crisis (Legido-Quigley et al., 2020), and very restrictive measures to control the pandemic might have been caused by the lack of adequate investments in the health systems (Kovac et al., 2020). Although the European Commission is highly proactive in strengthening solidarity, cooperation and exchange of information between the MS, the pandemic is showing the weakness of the EU in developing a common framework to respond to infectious disease outbreaks (Anderson et al., 2020).

The national governments reacted very differently during Spring 2020. In some cases, most of the countries closed restaurants, bars, hotels, schools, universities and borders, leaving open only those necessary activities such as pharmacies and supermarkets. Meanwhile, other nations followed a nothing-to-bedone approach in which citizens were uniformly informed about the consequences of the pandemic but voluntary good behaviour regarding basic measures rather than compulsory lockdowns prevailed (Paterlini, 2020). This uncoordinated approach is eroding the EU with more intensity than the recent immigrants' crisis, and Euroscepticism is coevolving with the rise of nationalism as EU citizens are seeing the European institutions as ineffective and useless (Celi et al., 2020; Creţan and Light, 2020). Thus, the EU is facing two opposite forces the resultant of which can be seen as the risk of disintegration vs. the opportunity for a 'Hamiltonian moment' that brings EU federalism in the near scene. Increasing our understanding on the determinants that affect citizens' opinions towards a more centralized approach to control the pandemic is of major importance from a regional policy perspective that can enhance the territorial resilience within the Union ${ }^{1}$.

The pandemic is affecting the EU countries very differently both in their economy and the health system. Kovac et al. (2020) highlight the deficient harmonized policy to control the pandemic for distinct issues such as collective action problems, information asymmetries, irrationality, negative externalities and persistent free-riding episodes. If the EU is once again unable to face the current crisis, some centrifugal forces that threat the EU integration might revive in the present with more populist ideas. The survival of the Union is highly dependent on how the EU is reacting to the crisis, and how the citizens perceive the benefits of the measures taken by the European institutions.

Many EU citizens opine that the EU should have more competences in dealing with the pandemic. Zalc and Maillard (2020) highlight the four top priority areas, namely to ensure that sufficient medical supplies are available for all EU MS (55\%);

\footnotetext{
${ }^{1}$ European Commission, Meeting of the Commission's Expert Group on Social Economy and Social Enterprises, 29 April 2020 (https://ec.europa.eu/growth/sectors/socialeconomy/enterprises/expert-groups_en).
} 
to allocate research funds to develop a vaccine (38\%); to provide direct financial support to the EU MS (33\%); and to improve co-operation between scientific researchers working across EU MS (32\%). The priority areas claim for mitigating division and, in this respect, a new climate that favours more than less European Union needs to be created among the heads of state and governments. Delors (2020) contends that the lack of European solidarity could mean the European Union's disappearance. In other words, the EU's credibility rests on its collective response to the coronavirus pandemic.

Thus, the current crisis poses an unprecedented challenge to the EU that will be crucial for its own survival. Kovac et al. (2020) discuss the centripetal and centrifugal forces as the jin-and-jang between the collective good provision and the existence of free-riders among the MS. The lack of competence of EU coordinated anti-COVID measures at union level exacerbates the collective action problem provision that deteriorates the image of the EU. Kovac et al. (2020) claim that the EU should add value in the search of better policies that control the spread of the pandemic.

Thus, it seems that the timing to analyse the main determinants that affect EU citizens' support that concur with that assumption is evident. Thus, the paper analyses the main determinants that are aligned with citizens' support to more Europe solutions. More European solutions will enhance and reinforce the EU's global regulatory power and influence in the world, facilitating the 'Brussels Effect' position (Bradford, 2020). Thus, the pandemic can be seen as a good opportunity to reposition the EU in the new geopolitical arena.

Moreover, the study is also circumscribed within the explicit call made by Bavel et al. (2020) regarding the need for research that could shed some insights that benefit policy makers in the fight against the pandemic. The paper contributes to the literature on EU federalism and resilience with the analysis of the main determinants that affect EU citizens' support towards the EU federalist solution to control COVID-19. The 'support' endogenous variable is analysed by the answers given to the question Q7 of a survey that studies different issues about the COVID in the EU: "To what extent do you agree with the following statement: the EU should have more competences to deal with crises such as the Coronavirus pandemic?"

The main determinants are studied according to a set of covariates that include sociodemographic factors such as country, gender, age, household size, no-children presence in the household, marital status, years of education, social class and job status as well as citizens' attitudes such as voting participation in the last EU elections, national government support, personal position on whether health benefits are greater than economic damage, personal position on being in favour of limiting individual rights, the use of apps to track people, own health concerns, others' health concerns, being affected by some economic loss, need of help from others, helping others, talking more to others and engaging online in COVID debates. 
Our study presents a number of advantages over other existing studies. Firstly, we directly examine the degree of citizens' support to control the pandemic throughout a 'more' European solution. The topic has also been analysed with other endogenous variables such as taxes, budget, fiscal policies, security and justice. Other studies have examined a similar topic with presidential vote intention or institutional trust as dependent variables (Jaakkola, 2019; Öberg, 2020; Oręziak, 2018; Snell and Jaakkola, 2016; Wendel, 2019). In this sense, Devine et al. (2020) contend that the pandemic has presented a unique opportunity to analyse the main theories in the trust literature. Secondly, our dataset is based on individual answers from a broad survey administered in 21 different EU countries; meanwhile the majority of the previous studies are only based in one country, so multinational comparisons are still scarce. In our case, it will be possible to analyse the existing differences at national level. And thirdly, we consider a very extensive set of potential explanatory variables that include interesting individual attitudes as well as social effects caused by the current pandemic. We also consider sophisticated covariates that measure the degree of acceptance of measures that limit the individual civil rights - movements ban and the use of people tracking apps.

\section{Literature review}

The literature review is divided in two subsections in order to clarify its reading.

\subsection{Absorptive, adaptive and transformative resilience}

Resilience has gained attention from urban and regional analysts (Martin, 2012) for four main reasons: a) the impact of natural and man-made disasters that have afflicted local communities; b) the influence of other disciplines, such as ecology, where the main interest is in how ecosystems respond to shocks; c) recognition that major disruptions can affect the whole economic landscape; and $\mathrm{d}$ ) the effect at both local and regional levels of financial and economic crises and their consequences, due to the austerity policies pursued by many states. Obviously, all the four main reasons have an important prevalence in the case of the current crisis.

COVID-19 is threatening the national health systems all over the world (Amat et al., 2020). The European Commission launched EU4Health ${ }^{2}$, an ambitious and dedicated funding programme for 2021-2027 which is based on the bitter lessons learned, with the aim to build resilient health systems in the EU and to better equip national health systems for the future. Through EU4Health, the EU will invest €9.4 billion in: tackling cross-border health threats, making medicines available and

\footnotetext{
${ }^{2}$ European Commission, EU4Health programme for a healthier and safer Union, 2020, (https://ec.europa.eu/commission/presscorner/detail/en/ip_21_1084).
} 
affordable and strengthening health systems. Capano (2020) discusses that only a few prepared and experienced countries, such as South Korea, Hong Kong, Taiwan, Australia and New Zealand were able to contain the virus transmission. These countries benefited from existing protocols that isolate hospitals, care facilities and senior residences; test and trace potential contagions; and store personal protective equipment (PPE). In the EU, countries were less prepared and the battle against the pandemic has been strongly influenced by the political debate and nuisance that existed in each of the countries.

Giovannini et al. (2020) make a summary of the strategic lessons that have been learnt by the Joint Research Centre in dealing with the concept of societal transformative resilience as a key element in the policy design that helps to cope with the current and future crises. Manca et al. (2017) provide a theoretical background that define the key vulnerability and resilience concepts that need to be permeated to policymaking. A 360-degrees system approach needs to be developed and interpreted holistically as many measures and indicators are affected by different government layers at national, regional and city levels. Depending on the duration of the shock and its effects, Giovannini et al. (2020) distinguish between absorptive, adaptive and transformative resilience. In the case of the current crisis, it seems evident that transformative resilience will probably prevail, and, for that reason, a successful society transformation can only be achieved by the commitment and support of citizens. The European Commission ${ }^{3}$ is recognizing in part such transformative resilience as the recovery plan for Europe will finance the reform and resilience plans focusing on the green and digital transformation.

Some national EU health systems, especially in Italy and Spain, have suffered from an unprecedented stress and the magnitude of the pandemic threat was falsely minimised by some politicians and policy makers. It is still unexplainable why other absorptive resilience plans implemented in other countries were not copied in and transferred to the EU. Pisano et al. (2020) conclude from the analysis of Italy that the virus spread does not wait for the containment measures (i.e. actions should be taken in extremely early phases), and that enough human and economic resources need to be deployed and coordinated among different actors from the society. Similarly, in the case of Spain, Legido-Quigley et al. (2020) find five important lessons that need to be learnt: (1) health regional systems need more financial resources; (2) the long term underinvestment in health services has stressed the system in the moment of necessity; (3) Spanish residents have responded very professionally so far but their demands need to be attended to guarantee this conduct in the near future; (4) Different government layers need to be better coordinated and politicians should not extract situational rents; (5) Spain will need to rearm its previously strong health sector.

3 European Commission, Financing the recovery plan for Europe, 2020, (https://ec.europa.eu/info/strategy/recovery-plan-europe_en). 
Djalante et al. (2020) contend that the crisis caused by the pandemic is aiming to the necessity of accelerating the integration of multiple global policy tools that are scattered across distinct international institutions. The Sendai Framework for Disaster Risk Reduction (SFDRR) is the successor instrument to the Hyogo Framework for Action (HFA) that was conceived to build the resilience of nations and communities to disasters (UNISDR, 2015). The SFDRR introduced a number of innovations changing the emphasis from disaster management to disaster risk management. Regarding the resilience of national health systems, the tool emphasized the role of the capacity of health workers in order to mitigate the work risks. It also highlighted governance as the second priority for action in order to ensure the coherence of different government layers that could affect the citizens' lives by laws, regulations and public policies.

So far there are numerous examples that show how the health workers have not been enough protected by the crisis committee. For example, Aubrecht et al. (2020) note that in Italy, Spain and New York, medical staff have faced significant shortages of personal protective equipment and pandemic outbreaks have been reported in some hospitals. Regarding the governance, coordination and coherence, the European picture is even more blurred. Verhofstadt (2020) contends that the European Directorate for Health and Food Safety and the European Medicine Agency can only provide recommendations to MS so they have tied hands in pandemic times. The collective action is still in the hands of 27 EU Health Ministers, and so far, the lack of coordination is causing that unique protocols to fight the pandemic do not exist in the union. In fact, the collective action problem and the associated free-riding phenomena lead to a suboptimal policy making (Kovac et al., 2020). In addition, the lack of coordination has provoked that some MS have been competing against each other in a cutthroat competitive medical supply market, and mutual accusations of interference and piracy behaviour have been frequent (Aubrecht et al., 2020).

If anything, the pandemic highlights that coordination and cooperation among different government layers is a priority for safeguarding the national health systems (Bursens, 2020; Goniewicz et al., 2020). In addition, future crises can be better handled if enough independent audits investigate the best approaches implemented in different public and private health subsystems such as clinics, hospitals and senior residences, in order to extract the important lessons learnt from the current pandemic. Kovac et al. (2020) analyse from an economic perspective important issues such as market failures, irrational decision-making, collective action problems and suboptimal allocation of competences that open the opportunity for a 'Hamiltonian moment' within the EU public policy in fighting the pandemic. 


\subsection{EU federalism}

Kelemen (2003) contends that European federalism research was dominated by comparative analysis, and concludes that comparative federalism was not helpful in finding the EU federal institutions that could start and influence the integration process or what reforms are needed to consolidate the idea of those scholars who view the EU as a well-defined polity. The EU is already a federal system, if federalism is understood as an institutional arrangement in which (a) public authority is divided between state governments and a central government, (b) each level of government has some issues on which it makes final decisions, and (c) a high federal court adjudicates disputes concerning federalism.

Evidently, Kovac et al. (2020) do not have the same definition in mind when they contend that the economics of federalism under "the current Covid-19 crisis of biblical proportions is particularly relevant by offering a powerful set of arguments for the EU to hold centralised, coordinative competences so as to reduce needless transaction and organisational costs, internalise negative spillovers and cross-border negative externalities while preventing any destructive, race-to-the-bottom or raceto-the-top competition among different political regimes in Member States. Hence, the arguments raised herein call for centralised EU action given sufficient support to enable it to become instrumental in containing the spread of the pathogen or mitigating its severity. In other words, outbreaks of pathogens and pandemics are one area in which the central EU level clearly has a comparative advantage with respect to lower levels of government (p.12)." The authors have clearly in mind a definition which expands the federal power, i.e., a shift in authority from MS to EU institutions.

In essence, all the layer governments are driven by the same preference relations that maximize both the set of competences and the citizens' support. The mentioned free-riding phenomena appear because each government is only concerned with the local support in each constituency and might pursue policies that only benefit their own constituents at the expense of other territorial constituents or the whole federation. Meanwhile, EU citizens are very heterogeneous but they will support the policy competence shift to whatever government layer they believe will produce their best subjective well-being. In the case of the pandemic, citizens will support more Europe solutions if they think EU is going to be more efficient than the respective national governments.

After-action reports and government commissions to investigate best practices and lessons learned from the COVID-19 pandemic have been advocated in many MS of the EU. Representatives of doctors, hospital, and retirement home networks called for a thorough audit of the division of competences in the public health domain. Anderson et al. (2020) contend that despite the high political commitment that exists in the EU to control the pandemic, it has been evident that a number of barriers have impeded the development of a more comprehensive European response and some 
dissonant national health measures have been common. The provisions within the EU treaty to control the pandemic beyond the national borders have proven to be inefficient and insufficient. National governments have prioritised their own health systems undermining the potential benefits of a more coordinated and centralized EU action. This is not a new phenomenon as the same selfish policies were seen during the H1N1 influenza pandemic in 2009, when some MS stockpiled vaccines and antivirals, and declined to share them with other countries (Nicoll and McKee, 2010). It seems obvious that from the lessons to be learnt from past complex public health emergencies, the EU is still far away from developing an appropriate public health reaction. To now neglect a more federal preparation for the next pandemics will repeat the same unwanted episodes.

Evidently, it is difficult to anticipate whether the "Hamiltonian moment" could be ignited after the unprecedented outbreak of COVID-19. There are different methods that range from social media and survey experiments to observational data that can be applied to analyse whether the centripetal or centrifugal forces prevail. If a "more EU" solution is pursued, the federalism economic theory could become a good starting point for the discussion on how best the EU can be organised (Inman and Rubinfield, 2020). Government action corrects as much as possible the market failures taking into account as the basic guiding principle to assign policy responsibility to the governmental layer which is more capable to accomplish the task at minimum cost.

Thus, the economic efficiency perspective determines the level of government which is best suited for taking action so the benefits/costs of decentralised/centralised political structures need to be balanced (Gerring and Veenendaal, 2020; Inman and Rubinfeld, 1997). The role of scale or size in structuring political outcomes should not be taken as granted, as every governmental layer has a designated population behind it that act as its main constituency with a mix of religions, ethnicities and races. Gerring and Veenendaal (2020) contend that federalism enhances electoral contestation, the regularity of leadership succession and professionalism, and attenuates clientelism and vote-buying. The authors claim that larger communities are less likely to concentrate political power, and institutions that rule over a large population are more likely to produce multiple and independent centres of power and less likely to take an interventionist approach in taxing, spending and regulating "a Madisonian characterization".

\section{Data and variables}

Our empirical analysis is based on a dataset obtained from a survey that was commissioned by the European Parliament and produced by Kantar (Zalc and Maillard, 2020). Kantar used an online access panel between 23 April and 1 May 2020 to obtain the European citizens' attitudes and opinions over the course of the COVID-19 pandemic. Thus, the Institute was able to collect a dataset with 21804 
respondents in 21 EU Member States; six Member States, Lithuania, Estonia, Latvia, Cyprus, Malta and Luxembourg, were not finally included in the analysis. The survey was limited to respondents aged between 16 and 64 for the majority of the countries, with the exception for Bulgaria, Czechia, Croatia, Greece, Hungary, Poland, Portugal, Romania, Slovenia and Slovakia where the respondents' age was between 16 and 54. Representativeness at the national level was ensured by quotas on gender, age, and region. The sample error at national level was guaranteed to be lower than 3.1 at a confidence level of 95 percent due to the sample size of about 1000 interviews (Table A1).

At the time of the survey's fieldwork, some measures taken against the pandemic were softly modulated in some countries such as Denmark, Germany and Austria, while in others like, for example, Italy and Spain, strict lockdown restrictions still persisted. The questionnaire was structured in four parts: (1) How EU citizens are coping with the crisis; (2) Attitudes towards European action; (3) Attitudes towards the national response; and (4) Personal situation and individual freedoms. As said, the construction of the dependent variable for the econometric model is based on the answers given to the question Q7 of the survey: "To what extent do you agree with the following statement: the EU should have more competences to deal with crises such as the Coronavirus pandemic?"

Table A2, in the appendix, shows the explanatory variables that are going to be used in the econometric model. It can be seen that there are 105 dummy variables for socio-demographic determinants that correspond to 9 distinct variables: (1) country; (2) gender; (3) household size; (4) age; (5) children presence in the household; (6) marital status; (7) terminal age of education; (8) social class; and (9) employment status. In addition, we also include in the model 12 more variables that are more related to different attitudes and citizens' behaviour: (1) the participation in the last 2019 May EU Election; (2) National Government support in general; (3) Personal position regarding whether the health benefits are greater or not than the economic damage; (4) Personal position regarding the recent limitations to individual freedom; (5) Personal position regarding the use of apps to fight the virus expansion; (6) Own health concern because of the coronavirus; (7) Health concern of family and friends because of the coronavirus; (8) Economic loss caused by the pandemic; (9) Respondents receive help from people around them; (10) Respondents help other people in need; (11) Respondents are talking more often to people on phone, social media or apps; (12) Respondents engage online in debates on the measures applied against the coronavirus.

The answer format scale for the question Q7 is based on a 5-point Likert scale formatted as follows: (1) Totally disagree; (2) Tend to disagree; (3) Don't know; (4) Tend to agree; and (5) Totally agree. Around two-thirds of respondents (69\%) want "the EU (to) have more competences to deal with crises such as the Coronavirus pandemic", while around a quarter (22\%) disagree with the statement. Agreement is highest in Portugal and Ireland, and lowest in Czechia and Sweden. 
The answer format scale for the independent variables can be extracted from Table A2. For example, it can be seen that for the social class variable, the response options are based on an 8-point semantic scales according to: (1) semi or unskilled manual worker; (2) skilled manual worker; (3) Supervisory or clerical/ Junior managerial/ Professional/ administrator; (4) Intermediate managerial/ Professional/ Administrative; (5) Higher managerial/Professional/Administrative; (6) Student; (7) Retired and living on state pension only; (8) Unemployed (for over 6 months) or not working due to long term sickness. For brevity and document extension, we omit the rest of the format answer scales.

\section{Econometric model. Results}

The dependent variable for the econometric model is based on the answers given by the respondents to Q7 that deals with the citizens' agreement on the fact that the EU should have more competences to deal with crises such as the Coronavirus pandemic. As the responses are given in an ordinal scale of 5 points, we decide to use a heteroskedastic ordered probit model as the best approach to analyse the main determinants to explain the citizens' support towards more EU response instead of national responses. Homoscedastic ordered probit models assume that error variances are constant across observations, and this is a very strong assumption that can lead to biased parameter estimates in addition to miss-specified standard errors, so the analysis of heteroskedastic ordered probit models is highly recommended (Reardon et al., 2017). Some authors have also speculated that unmeasured variables can affect more the probability of more federalists' support for some segments that could depend on a number of sociodemographic factors such as age or social class, then it will be inappropriate to consider that the model is homoscedastic (Williams, 2010).

In the current study, the heteroskedastic ordered probit model can be explained as the result of a latent variable model. Let $y$ denote the random variable whose value ranges from 1 to 5 , and the order of the values means that citizens are more EU federalists with the anti-COVID-19 measures. Thus, the nature of the latent variable $y^{*}$ is determined by:

$$
\begin{aligned}
& y^{*}=x \beta+\sigma \varepsilon \\
& \sigma=\exp (x \delta)
\end{aligned}
$$

where $\mathrm{x}$ is a vector formed by the dummy variables included in the model as the determinant factors, beta and delta are two vectors of parameters to be estimated by the model, $\varepsilon$ is the error term that distributes as a standard normal distribution, and $\sigma$ is the scale parameter that allows the variance of the error term to vary for the heteroskedastic models. The model now determines four threshold parameters 
$\mu_{1}<\mu_{2}<\mu_{3}<\mu_{4}$ that permit to link the observed dependent variable with the unobserved latent variable as follows:

$$
\begin{array}{ll}
y=1 & \text { if } y^{*} \leq \eta_{1} \\
y=2 & \text { if } \eta_{1}<y^{*} \leq \eta_{2} \\
y=3 & \text { if } \eta_{2}<y^{*} \leq \eta_{3} \\
y=4 & \text { if } \eta_{3}<y^{*} \leq \eta_{4} \\
y=5 & \text { if } \eta_{4}<y^{*}
\end{array}
$$

The parameters are $(1 \leq i \leq 5)$ estimated by maximizing as usual the loglikelihood function which are consistent and asymptotically normal. The probability of observing a particular outcome, for $(1 \leq i \leq 5)$ is given by:

$$
\begin{aligned}
P\left(y_{i}=j \mid x_{i}\right) & =P\left(\eta_{j-1} \leq y_{i}^{*} \leq \eta_{j}\right) \\
& =P\left(\eta_{j-1}-x_{i} \beta \leq \varepsilon_{i} \leq \eta_{j}-x_{i} \beta\right) \\
& =F\left(\eta_{j}-x_{i} \beta ; \sigma\right)-F\left(\eta_{j-1}-x_{i} \beta ; \sigma\right)
\end{aligned}
$$

where $\mathrm{F}$ is the cumulative normal distribution function assumed for the error term, $\eta_{0}=-\infty$, and $\eta_{5}=\infty$. Then we can write the log-likelihood function as follows:

$$
\log L=\sum_{i=1}^{N} \sum_{j=1}^{5} y_{i j} \log \left[F\left(\eta_{j}-x_{i} \beta ; \sigma\right)-F\left(\eta_{j-1}-x_{i} \beta ; \sigma\right)\right]
$$

The log likelihood is maximized with respect to the parameters of the distribution function and the cut thresholds. The homoscedastic model can lead to inconsistent and biased estimators. The specification of categorical variables (normalization) in choice or ordinal models is an issue that has received a lot of attention because of the existing linear dependency problem (Daly et al., 2016; Green and Hensher, 2010; Hensher et al., 2015). In most of the papers that use ordered probit models, dummy coding is the most recurrent normalization. Nevertheless, for reasons of interpretability and the confounding effects with the constant or the threshold cut points, Hensher et al. (2015) claim that effects coding normalization is superior to dummy coding. Daly et al. (2016) refine the effects code normalization with a more stable reference point referring all the categories to a permanent zero definition specified by the population-weighted average instead of all the category-weighted averages, and, thus, the comparisons are more valuable. For this reason, we decide to normalize all the variables with the effects coding proposed by Daly et al. (2016). 
Table A3 in the appendix report the estimation results for the heteroskedastic model. It is well known that the absolute magnitude of the estimated parameters is uninformative, and for that reason, the marginal effects of the determinants on the probability of the outcome of answering 'totally agree' will be commented. In this case, the marginal effects depend on the sign of the relevant coefficients, the relative value of the mean of the latent variable and the respective threshold parameters.

It can be seen that many coefficients for the countries are significant in both the latent model and the observed heterogeneity. For the rest of the determinants included in the analysis, there is at least one coefficient in the set of the dummy variables of each determinant for which the coefficient for the latent model or the variance is significant. All the threshold parameters are also significant. Finally, we test whether the heteroskedastic model is statistically different from the homoscedastic model using a likelihood ratio test concluding, unsurprisingly, that the heteroskedastic model is different and improves significantly the model fit $\left(\mathrm{Df}=101\right.$, Chisq=1913.6, Pr $\left.>2.210^{-16 * * *}\right)$. Table A4 shows the marginal effects for the outcome 5 (totally agree class). The rest of the marginal effects were also calculated and are available upon request, but in order to summarize the results we have preferred to highlight only the marginal effects of the outcome 5.

Figure 1 in the appendix presents schematically the summary of the results. It can be seen that the following determinant does not present significant effects: (1) Household size. In summary, from the 21 variables included in the analysis, we conclude that only the household size does not have any significant effect on the probability of being "totally agree" with the federalists' position about the EU measures against COVID-19. The analysis of positive determinants and negative drawbacks to have a federalist's position with respect to the average EU citizen shows that: (1) regarding the nationality, Portugal (13\%), Bulgaria (12\%), Greece and Italy (9\%) have a more federalist position in comparison with the citizens of Germany and the Netherlands(-4\%), Finland (-8\%), Croatia (-10\%), Czech Rep. and Sweden (-12\%); (2) Females (-2\%) are less supportive to federalist positions; (3) Young citizens of 16-24 years old are more federalists (5\%) and those with an age range between 35-64 are less federalists (-2\%); (4) No children presence shows a less federalist position (-0.5\%); (5) Living with other adults is a driver (3\%) for being more federalists than the average; (6) Respondents with sixteen years of education or less are more federalists; (7) Regarding the social class we find drivers and drawbacks for federalism (Supervisory or clerical (-2\%), Unskilled and skilled manual worker (2\%) and Retired (5\%)); (8) Meanwhile for the job status we find only drawbacks for those who are still in school or in higher education $(-3 \%)$ and not working and not seeking work $(-2 \%)$.

Regarding the attitudes and behaviour, the analysis shows that there are drivers and drawbacks for the federalist position as follows: (1) those who voted in the last EU election are more federalists than the average (0.7\%); (2) Regarding the partisanship (the total governmental support), there is not a clear distinction as those 
who totally support (4\%) or totally oppose (3\%) are more federalists than the average but those who tend to oppose (-1\%) are less federalist than the average; (3) The citizens who focus more on the economic damage than on the health benefits $(8 \%)$ are more federalists; (4) The opposition to limit any individual right decreases the probability of being more federalists; (5) A similar pattern is observed for those who oppose to the use of apps to trace people $(-2 \%$ and $-3 \%)$ in comparison with those who are strongly in favour of the use (8\%); (6-7) those who are fairly concerned about their own health or the health of others (family and friends) have between two and three points more probability of being federalists; in contrast, those who are not concerned show a less supportive position to federalism; (8) Those who are suffering an income loss effect are less federalists than the average citizen; (9-10) being helped or helping others act as a driver towards federalism; and (11-12) talk more to others and being engaged in online COVID debates is also positively correlated with more federalist positions.

Figure 2 in the appendix shows the map with the marginal effects for the EU federalism position to deal with COVID-19 crisis of the $21 \mathrm{EU}$ countries included in the dataset for the "totally agree outcome". Once again, it can be seen that there exists a clear division between the countries which seem to present a more federalist position like Portugal, Bulgaria, Greece, Italy, Romania, Belgium, France, Ireland, Slovenia and Spain; those countries which show a similar position as the average EU citizen: Denmark, Poland and Hungary; and finally the countries which show more reticence to shift the power from national governments to the EU federation: Austria, Netherlands, Germany, Slovakia, Finland, Croatia, Czech and Sweden.

\section{Discussion}

Goniewicz et al. (2020) contend that the management of anti COVID measures has proven to be a formidable challenge for many countries in the EU. Governments play a central role in controlling pandemics by adopting different measures such as borders' closures and significant limitations on both the mobility of people and economic activity especially for bars, restaurants and accommodation establishments that impose costs and sacrifices to citizens and firms. Lessons learned to date from COVID-19 in the EU are many and the current crisis has highlighted the need to think about whether future pandemics could be better addressed by more European solutions -the federalist vision. from a population-based management approach and apply outside the box critical thinking. The pandemic events show how global leaders in healthcare, government and business will need to pivot from local and single approaches to multilateral decision-making that embraces multidisciplinary and transdisciplinary levels of cooperation. This cooperation requires courage and leadership to change the status-quo solutions which have proven to be erroneous. 
This study analyses the main determinants that explain the main drivers and drawbacks that exist in $21 \mathrm{EU}$ countries for the support of more federalist anti COVID-19 measures taken by the supranational entity. Figure 1 shows that there are 20 determinants (sociodemographic, attitudes and behaviour) that affect significantly the probability of being more federalist than the average EU citizen regarding the future participation of the EU to control similar crises to the current pandemic. By magnitude order, the main determinants observed are for the following countries: Portugal, Bulgaria, Greece, Italy and Romania; being strongly in favour of the use of apps to control the pandemic; those who think that the economic damage is greater than the health benefits; those who definitely participate more in online debates about the pandemic; those with an age between 16-24 years old; those who are retired and living on state pension only. Meanwhile, the main drawbacks in magnitude are observed for the country of residence in Slovakia, Finland, Croatia, Czech Republic and Sweden.

Amat et al. (2020) analyse the citizens' response to the democratic dilemmas that exist on the use of lockdowns enforcements that suppose an alteration of the preexisting civil liberties context. They conduct a series of experiments in Spain during the last week of March 2020 and find that citizens in Spain have a strong preference for a national response in comparison to an EU response, and this finding is much stronger for the pandemic than for other global problems such as climate change or international terrorism. These results contrast with those obtained in the current study, as in our case, Spanish citizens show two additional points of being more federalists in comparison with the average EU citizen. Regarding the results obtained for Portugal, Bulgaria, Greece, Italy and Romania, it is difficult to find other multinational studies of a similar nature. We can only speculate that the causes to observe such differences between these countries and the average EU citizen could be rooted in three distinct categories: (1) Relief packages that mitigate the economic consequences of the pandemic and its uneven distribution can be better addressed at the EU level; (2) a strong demand for strong leadership that could impulse the 'Brussels effect'; and (3) a sharp support for a more collective action that can be aligned with technocracy.

Most of the MS of the EU have imposed quarantines and lockdowns as a way to control the contagious nature of the virus. The enforcement of these measures has been accompanied with invasive surveillance equipment that limits the civil rights. In the EU, we are witnessing the use of drones to control the physical distance in public space, as well as voluntary smartphone-based individual tracking apps. We find that those citizens willing to trade-off civil rights and individual freedoms in exchange for protection against the pandemic are more federalists than the average EU citizen. Woo (2020) analyses the TraceTogether app developed by Singapore government that relies on Bluetooth technology to keep track of the people who can be in contract with people infected with coronavirus and suggests that the app was not a success because of a lack of technological literacy among citizens but more 
likely due to concerns over data privacy and a lack of trust in the government's ability to safeguard individuals' personal data. Thus, it seems obvious that federalism and institutional trust are interlinked. The EU needs to exhibit a significant level of socio-political trust that should be based upon the ability to generate a more prosperous well-being of EU citizens.

There is not a generalized consensus about the overall efficacy of anti-COVID measures taken by different governments (Aubrecht et al., 2020; Ylli et al., 2020). Most governments have taken similar measures to limit the spread of the pandemic having in mind the associated costs caused on the economy such as staying at home policies or hard restrictions in economic activities. The most severe interventions have caused a polarization on the society between those who think that health benefits are greater than the economic damage and those who think that the economy should also be maintained. Rapid and massive testing can be an alternative to the most severe containment measures. Nevertheless, it is not easy for the society to evaluate the benefits of saving lives on the short-run vs. the long-run economic costs so it seems inevitable that the society is divided between these two extremes. Containment measures in the short term save lives but the associated economic recession might reduce the well-being and life expectancy of the citizens. Gourinchas (2020) puts this nicely as "flattening the infection curve inevitably steepens the macroeconomic recession curve" (p. 32). Tepe et al. (2020) analyse how the policies to minimize the number of deaths in Germany depend on the information provided to the respondents regarding the economic damage and the civil rights limitations. The authors find that both treatments reduce the support of the saving lives measures and that the economy frame reduction is greater than the freedom frame. Our results show that those who think that the economic damage is greater than the health benefits are more federalists than the average EU citizen, and this can be explained by the fact that the lack of coordination at the EU level has facilitated the piecemeal nation-by-nation approach that has closed bars, restaurants, schools and non-essential economic activities. This has reinforced the citizens' image of the macroeconomic recession curve which inevitable makes them look at the EU and the European Central Bank (ECB) for avoiding the risk of another debt crisis pooling multilateral guarantees for new debt emissions.

The results of being more federalists for those who definitely participate more in online debates about the pandemic can be probably explained by the concept of deliberative democracy as the communicative process of opinion and will-formation in which citizens seek to convince each other by reasoning on debates, and are willing to revise their own opinion after others' opinions (Chambers, 2003; Steffek, 2014). The popularity of deliberative democracy in the case of the EU is well grounded in its own creation as the integration project has always highlighted the epistemic quality as well as the practical orientation to enhance the Europeans quality of life. Mendonça et al. (2020) contend that non-verbal modes of communication can also contribute to deliberative democracy when they (1) serve 
as part of reason-giving processes, (2) give the word to marginalized actors in public debates and (3) induce reflection and encourage new ways of thinking about the public controversies at hand.

Our results regarding the young generation are concordant with those of Sloam and Henn (2019). The authors show that young cosmopolitans in the UK opposed firmly to BREXIT (British exit from the EU), and that their support for EU membership was not directly imbricated by a sense of European identity, but with their relative acceptance of cultural diversity and European integration, and their fears of the negative economic consequences in an era of austerity and falling living standards. With regard to age, the authors find that the vast majority of young people - 69\% of 18-30 year olds and 76\% of 18-21 year olds - voted for the UK to remain in the EU. In addition, our results for retired and living on state pension only can be explained by the fact that the mortality rate has been much higher among the eldest, so they may be particularly more supportive of the comparative advantage that a central coordinated response at EU level can have over the national measures taken. Similarly, Pierre (2020) finds that in the Swedish case the national measures have been flawed because protecting the elderly in nursing homes and elsewhere was not properly implemented. Thus, the institutional relationships among the Swedish public health system and the elderly care sector have been clearly damaged.

Interestingly, the main drawbacks in magnitude are only observed for some nationals of the countries such as Slovakia, Finland, Croatia, Czech Republic and Sweden. We compare our results with those expressed in the newsletter on 23 June 2020 from DG Communication's Public Opinion Monitoring Unit that is focused on the impact of the COVID-19 pandemic on public opinion within the European Union (Schulmeister, 2020). For example, respondents in Slovakia trust the news less than they did one year ago. They are also reading less newspapers than in the past. In the case of Czechia, a third of respondents saw a decline in their household income between the beginning of the pandemic and May. Almost half of employees experienced the negative effects of the coronavirus crisis in the form of working time restrictions or even job losses, and three quarters of self-employed workers reported a reduction in orders or the need to close down. In the case of Sweden, trust in the government's management of the crisis is stable, around $46 \%$, and the concerns over the consequences of the crisis are decreasing up to $40 \%$ of respondents who answered they are worried. The Croatian case has even been aggravated by an earthquake occurred in Zagreb of 5.5 Richter magnitude on 22 March 2020 (Rok et al., 2020). Nevertheless, the Ministry of Health could deploy medical personnel according to the needs, and as in many MS of the EU, the health care workers have got COVID-19 but they have been very professional in taking care of their duties, so the health system has not been in jeopardy. Finally, the case of Finland is paradigmatic as the country belongs to the group of states with a high health security capacity and a relatively low pandemic mortality rate (Moisio, 2020). The author contends that the territorialisation of the pandemic around the seemingly coherent 
nation-state hence fundamentally characterizes COVID-19 geopolitics in Finland, and the pandemic, itself, has even been articulated with references to war and as a national security issue.

\section{Conclusions}

This paper empirically tests the citizens' support for a more centralized EU anti-COVID response to contain the negative effects of the pandemic and mitigate the economic impacts. According to Kovac et al. (2020), the pandemics can be better contained at supranational EU level in comparison with lower layers of government such as national or regional levels. To that aim, we estimate an ordinal heteroskedastic probit model using a dataset compiled from a survey of citizens of 21 EU MS. The federal support varies very much by country, and our results show that some countries such as Portugal, Bulgaria, Greece, Italy and Romania have citizens who are more federalists than the average EU citizen, and for Slovakia, Finland, Croatia, Czech Republic and Sweden, the citizens are less federalists. Our results also show that by order of magnitude the citizens who are more federalist than the average EU citizen are those: (1) who are strongly in favour of the use of apps to control the pandemic; (2) who think that the economic damage of the containment measures is greater than the health benefits; (3) who definitely participate more in online debates about the pandemic; (4) with an age between 1624 years old; and (5) who are retired and living on state pension only.

Our micro-econometric analysis shows that there are 20 determinants that affect the highest citizens' support (those who answered totally agree) to a more EU solution in $21 \mathrm{EU}$ countries. Interestingly, there is only one determinant, household size, that does not significantly affect the citizens' federalist position. The results provide valuable insights on how the related role of the EU in containing the spread of the pandemic is seen by those who are in favour of a more centralized and coordinative role (federalist position) vs. those who are not in favour of this (nationalist or regionalist position). These two positions can be seen as the crossroads that the EU is facing between the risk of disintegration and the opportunity for a Hamiltonian moment (Celi et al., 2020). The authors contend that the current darkened geopolitical situation requires that the EU acts jointly, and that the inter and intra country political struggles and conflicting interests do not interfere into the potential moment that exists in the union. Beetz (2019) contends that European popular sovereignty demands the shift of political power from the MS to the European level. Advocates of a European federation rely upon the conception of popular sovereignty. Although some theorists have already posited a historical European community, another argumentative line can be further explored to transform the power of democratic institutions with the base of the European polity. The combination of this with a statist conception of sovereignty justifies a unification project in which MS become regions in a sovereign European Federal State. 
Our econometric analysis from a methodological point of view clearly supports the empirical evidence regarding the better fit that is obtained by the heteroskedastic ordinal probit model. The model also provides unbiased estimates for the main determinants that explain the federalist position of the EU role in controlling the pandemic. These results are in line with other studies that have been applied in other contexts (Lemp et al., 2011; Reardon et al., 2017). The improvements to the homoscedastic ordered probit model are important as the insights obtained from ordered choice estimation can mislead the policy guidance.

This study presents a number of possible extensions for future research. For example, the possible drivers for the Hamiltonian moment in the EU after the pandemic can also be analysed for other contexts and structures such as federal courts, judicial systems, the ECB, the Europol, the European army, fiscal policy, immigration policy, international affairs, environmental regulation, and other intangibles as the European passport, as a way to reinforce the European identity. Menon and Schain (2006) present an interesting contribution to the literature of comparative federalism through a systematic comparison of the institutions, policies, and developmental trajectories of the European Union and the United States. The authors emphasize the dynamics that have caused a developmental change in each federation. Burgess (2003) contends that federations usually face a crossroads with two possible directions: aggregation and disaggregation. The current study has transferred two iconic figures of the aggregation process of the United States to the case of the EU coined as Hamiltonian and Madisonian moments. Both terms are coined after the Federalist Papers written for the Philadelphia Convention by illustrious economists and philosophers like Alexander Hamilton and James Madison. The papers published between 1787 and 1788 are considered the cradle for federalism which is based on the separation of powers and on the system of checks and balance. It will be necessary in the EU to create the framework for such dynamic change with a need on more efficient management of common interests and a progressive transformation of the European market into a political entity. Thus, new founding parents for the EU federation to substitute Jean Monnet and Robert Schuman are despairingly needed.

Acknowledgments: The authors acknowledge Eurofound for providing the dataset "Living, working and COVID-19". Without the dataset, this study would have not been possible.

\section{References}

Amat, F., Arenas, A., Faló-Gimeno, A. and Muñoz, J. (2020), Pandemics meet democracy: Experimental evidence from the COVID-19 crisis in Spain, Working Paper, Preprint (retrieved from https://osf.io/preprints/socarxiv/dkusw/). 
Anderson, M., Mckee, M. and Mossialos, E. (2020), Covid-19 exposes weaknesses in European response to outbreaks, BMJ, 368, m1075. https://doi.org/10.1136/bmj.m1075

Aubrecht, P., Essink, J., Kovac, M. and Vandenberghe, A.S. (2020), Centralized and Decentralized Responses to COVID-19 in Federal Systems: US and EU Comparisons, Law \& economics of Covid-19 Working Paper series, 04.

Beetz, J.P. (2019), Safeguarding, shifting, splitting or sharing? Conflicting conceptions of popular sovereignty in the EU-polity, Journal of European Integration, 41(7), pp. 937-953. https://doi.org/10.1080/07036337.2019.1665662

Bradford, A. (2020), The Brussels effect: How the European Union rules the world, Oxford (UK): Oxford University Press. https://doi.org/10.1093/oso/9780190088583. $\underline{001.0001}$

Bursens, P. (2020), Federalism and the COVID-19 crisis: Reflections on competences, actors and party politics in Belgium, Revista Cuadernos Manuel Giménez Abad, 19, pp. 1416 (retrieved from https://dialnet.unirioja.es/servlet/articulo?codigo=7453309).

Capano, G. (2020), Policy design and state capacity in the COVID-19 emergency in Italy: if you are not prepared for the (un)expected, you can be only what you already are, Policy and Society, 39(3), pp. 326-344. https://doi.org/10.1080/14494035.2020. $\underline{1783790}$

Celi, G., Guarascio, D. and Simonazzi, A. (2020), A fragile and divided European Union meets Covid-19: further disintegration or 'Hamiltonian moment'?, Journal of Industrial and Business Economics, 47(3), pp. 411-424. https://doi.org/10.1007/s40812-020-00165-8

Chambers, S. (2003), Deliberative democratic theory, Annual review of political science, 6(1), pp. 307-326. https://doi.org/10.1146/annurev.polisci.6.121901.085538

Creţan, R. and Light, D. (2020), COVID-19 in Romania: transnational labour, geopolitics, and the Roma 'outsiders', Eurasian Geography and Economics, 61(4-5), pp. 559-572. https://doi.org/10.1080/15387216.2020.1780929

Daly, A., Dekker, T. and Hess, S. (2016), Dummy coding vs effects coding for categorical variables: Clarifications and extensions, Journal of Choice Modelling, 21, pp. 36-41. https://doi.org/10.1016/j.jocm.2016.09.005

Delors, J. (2020), Coronavirus pandemic infects Europe with 'germ of division' (retrieved from delorscentre.eu).

Devine, D., Gaskell, J., Jennings, W. and Stoker, G. (2020), Trust and the Coronavirus Pandemic: What are the Consequences of and for Trust? An Early Review of the Literature, Political Studies Review, 1478929920948684. https://doi.org/10.1177/1478929920948684

Djalante, R., Shaw, R. and DeWit, A. (2020), Building resilience against biological hazards and pandemics: COVID-19 and its implications for the Sendai Framework, Progress in Disaster Science, 6, 100080. https://doi.org/10.1016/j.pdisas.2020.100080 
Gerring, J. and Veenendaal, W. (2020), Population and politics: The impact of scale, Cambridge (UK): Cambridge University Press. https://doi.org/10.1017/ $\underline{9781108657099}$

Giovannini, E., Benczur, P., Campolongo, F., Cariboni, J. and Manca, A. (2020), Time for transformative resilience: the COVID-19 emergency, EUR 30179 EN, Luxembourg: Publications Office of the European Union. https://doi.org/10.2760/062495

Goniewicz, K., Khorram-Manesh, A., Hertelendy, A.J., Goniewicz, M., Naylor, K. and Burkle, F.M. (2020), Current response and management decisions of the European Union to the COVID-19 outbreak: a review, Sustainability, 12(9), p. 3838. https://doi.org/10.3390/su12093838

Gourinchas, P. (2020), Flattening the recessions and the pandemic curves, in: Baldwin, R.E. and Weder, B. (eds.), Mitigating the Covid Economic Crisis, Act Fast and Do Whatever it Takes, London (UK): CEPR Press, pp. 31-40.

Greene, W.H. and Hensher, D.A. (2010), Modeling Ordered Choices: A Primer, Cambridge (UK): Cambridge University Press. https://doi.org/10.1017/CBO9780511845062

Hensher, D.A., Rose, J.R. and Greene, W.H. (2015), Applied Choice Analysis, Cambridge (UK): Cambridge University Press. https://doi.org/10.1017/CBO9781316136232

Inman, R.P. and Rubinfeld, D.L. (1997), Rethinking federalism, Journal of economic perspectives, 11(4), pp. 43-64. https://doi.org/10.1257/jep.11.4.43

Inman, R.P. and Rubinfeld, D.L. (2020), Democratic Federalism: The Economics, Politics, and Law of Federal Governance, Princeton (NJ): Princeton University Press.

Jaakkola, J. (2019), A Democratic Dilemma of European Power to Tax: Reconstructing the Symbiosis Between Taxation and Democracy Beyond the State?, German Law Journal, 20(5), pp. 660-678. https://doi.org/10.1017/glj.2019.55

Kelemen, R.D. (2003), The structure and dynamics of EU federalism, Comparative Political Studies, 36(1-2), pp. 184-208. https://doi.org/10.1177/0010414002239376

Kovac M., Elkanawati, A., Gjikolli, V. and Vandenberghe, A-S. (2020), The Covid-19 pandemic: collective action and European public policy under stress, Central European Journal of Public Policy, 14(2), pp. 47-59. https://doi.org/10.2478/cejpp$\underline{2020-0005}$

Legido-Quigley, H., Mateos-García, J.T., Campos, V.R., Gea-Sánchez, M., Muntaner, C. and McKee, M. (2020), The resilience of the Spanish health system against the COVID19 pandemic, The Lancet Public Health, 5(5), pp. 251-252. https://doi.org/10.1016/S2468-2667(20)30060-8

Lemp, J.D., Kockelman, K.M. and Unnikrishnan, A. (2011), Analysis of large truck crash severity using heteroskedastic ordered probit models, Accident Analysis \& Prevention, 43(1), pp. 370-380. https://doi.org/10.1016/j.aap.2010.09.006

Manca, A.R., Benczur, P. and Giovannini, E. (2017), Building a scientific narrative towards a more resilient EU society. Part I: a conceptual framework. Luxemburg: Publications Office of the European Union. https://doi.org/10.2760/635528 
Martin, R. (2012), Regional economic resilience, hysteresis and recessionary shocks, Journal of Economic Geography, 12(1), pp. 1-32. https://doi.org/10.1093/jeg/lbr019

Mendonça, R.F., Ercan, S.A. and Asenbaum, H. (2020), More than Words: A Multidimensional Approach to Deliberative Democracy, Political Studies. https://doi.org/10.1177/0032321720950561

Menon, A. and Schain, M. (2006), Comparative federalism: the European Union and the United States in comparative perspective, Oxford (UK): Oxford University Press.

Moisio, S. (2020), State power and the COVID-19 pandemic: the case of Finland, Eurasian Geography and Economics, 61(4-5), pp. 598-605. https://doi.org/10.1080/15387216.2020.1782241

Nicoll, A. and McKee, M. (2010), Moderate pandemic, not many dead-learning the right lessons in Europe from the 2009 pandemic, European Journal of Public Health, 20(5), pp. 486-488. https://doi.org/10.1093/eurpub/ckq114

Öberg, J. (2020), Trust in the Law? Mutual Recognition as a Justification to Domestic Criminal Procedure, European Constitutional Law Review, 16(1), pp. 33-62. https://doi.org/10.1017/S1574019620000036

Oręziak, L. (2018), Fiscal federalism and a separate budget for the euro area, International Journal of Management and Economics, 54(2), pp. 85-98. https://doi.org/10.2478/ijme-2018-0012

Paterlini, M. (2020), 'Closing borders is ridiculous': the epidemiologist behind Sweden's controversial coronavirus strategy, Nature, 580(7805), p. 574. https://doi.org/10.1038/d41586-020-01098-X

Pierre, J. (2020), Nudges against pandemics: Sweden's COVID-19 containment strategy in $\begin{array}{llll}\text { perspective, Policy } \quad \text { and } & \text { Society, 39(3), } & \text { 478-493. }\end{array}$ https://doi.org/10.1080/14494035.2020.1783787

Pisano, G.P., Sadun, R. and Zanini, M. (2020), Lessons from Italy's response to coronavirus, Harvard Business Review (retrieved from online at hbr.org).

Reardon, S.F., Shear, B.R., Castellano, K.E. and Ho, A.D. (2017), Using heteroskedastic ordered probit models to recover moments of continuous test score distributions from coarsened data, Journal of Educational and Behavioral Statistics, 42(1), pp. 3-45. https://doi.org/10.3102/1076998616666279

Rok, Č., Alemka, M. and Krunoslav, C. (2020), Earthquake in the time of COVID-19: The story from Croatia (CroVID-20), Journal of Global Health, 10(1), p. 010349. https://doi.org/10.7189/jogh.10.010349

Schulmeister, P.M. (2020), Public opinion monitoring at a glance in the time of COVID-19, Newsletter 23 June 2020, Brussels: European Parliament.

Sloam, J. and Henn, M. (2019), Young Cosmopolitans Against Brexit, in: Sloam, J. and Henn, M. (eds.), Youthquake 2017: The Rise of Young Cosmopolitans in Britain, Cham (UK): Palgrave Pivot, pp. 71-87. 
Snell, J. and Jaakkola, J. (2016), Economic mobility and fiscal federalism: taxation and European responses in a changing constitutional context, European Law Journal, 22(6), pp. 772-790. https://doi.org/10.1111/eulj.12212

Steffek, J. (2014), Civil society participation and deliberative democracy in the European Union, E-international Relations, 21 (retrieved from https://www.eir.info/2014/03/21/civil-society-participation-and-deliberative-democracy-in-theeuropean-union/).

Tepe, M., Vanhuysse, P., Jankowski, M., Juen, C.M. and Erlbruch, F. (2020), Pandemic Balancing Acts: Early COVID-19 lockdown changes how Germans trade off lives and weigh constitutional powers (retrieved from https://osf.io/geu52).

UNISDR (The United Nations Office for Disaster Risk Reduction) (2015), Sendai Framework for Disaster Risk Reduction 2015 - 2030, Geneva: UNISDR (retrieved from https://www.preventionweb.net/files/43291_spanishsendaiframeworkfordisasterri.pdf).

Van Bavel, J.J., Baicker, K., Boggio, P.S., Capraro, V., Cichocka, A., Cikara, M., ... and Willer, R. (2020), Using social and behavioural science to support COVID-19 pandemic response, Nature human behaviour, 4(5), pp. 460-471. https://doi.org/10.1038/s41562-020-0884-Z

Verhofstadt, G. (2020), Time of coronavirus shows importance of being European (retrieved from euobserver.com).

Wendel, M. (2019), Mutual Trust, Essence and Federalism-Between Consolidating and Fragmenting the Area of Freedom, Security and Justice after LM, European Constitutional Law Review, 15(1), pp. 17-47. https://doi.org/10.1017/S1574019619000063

Williams, R. (2010), Fitting heterogeneous choice models with oglm, The Stata Journal, 10(4), pp. 540-567. https://doi.org/10.1177/1536867X1101000402

Woo, J.J. (2020), Policy capacity and Singapore's response to the COVID-19 pandemic, Policy and Society, 39(3), pp. 345-362. https://doi.org/10.1080/14494035.2020.1783789

World Health Organisation (2020a), Coronavirus Disease 2019 (COVID-19) Situation Report, 51, Geneva: World Health Organization (retrieved from https://apps.who.int/iris/handle/10665/331475).

World Health Organisation (2020b), WHO Director-General's Opening Remarks at the Media Briefing on COVID-19-11 March 2020. Geneva: World Health Organization (retrieved from https://www.who.int/director-general/speeches/detail/who-directorgeneral-s-opening-remarks-at-the-media-briefing-on-covid-19---11-march-2020).

Ylli, A., Wu, Y.Y., Burazeri, G., Pirkle, C.M. and Sentell, T. (2020), The lower COVID-19 related mortality and incidence rates in Eastern European countries are associated with delayed start of community circulation (retrieved from medRxiv).

Zalc, J. and Maillard, R. (2020), Uncertainty/EU/Hope, Public opinion in times of COVID19, Brussels: European Union. https://doi.org/10.2861/087976 


\section{Online appendix}

Table A1. Sample features

Table A2. Definitions of the independent variables

Table A3. Heteroskedastic model

Table A4. Marginal effects for 'Totally agree' category regarding that the EU should have more competences

Figure 1. Marginal effects for the EU federalism position to deal with COVID-19 crisis. Totally agree outcome

Figure 2. Map with the marginal effects for the EU federalism position to deal with COVID-19 crisis. Totally agree outcome

https://ejes.uaic.ro/appendix/EJES2021_12SI_MAR_A01.pdf 